\title{
THE DOLLAR/EURO EXCHANGE RATE AND A COMPARISON OF MAJOR MODELS
}

\author{
Yu Hsing ${ }^{1}$, Bruno S. Sergi ${ }^{2}$ \\ ${ }^{1}$ Southeastern Louisiana University, Hammond, Louisiana 70402, USA \\ ${ }^{2}$ University of Messina, DESMaS “V. Pareto”, Via T. Cannizzaro, 27898122 Messina, Italy \\ E-mails: ${ }^{1} y$ hsing@selu.edu; ${ }^{2}$ bsergi@unime.it \\ Received 2 December 2008; accepted 13 April 2009
}

\begin{abstract}
This article analyzes the behaviour of the USD/EUR exchange rate based on four major models. Using the mean absolute percent error (MAPE) as a criterion, the extended Mundell-Fleming model performs best, followed by the PPP model using the relative PPI, the monetary model, the PPP model using the relative CPI, and the UIP model. The widely used log-log form in the PPP model based on the relative PPI or CPI can be rejected at the $5 \%$ level. The insignificant coefficients or unexpected signs of some variables in the monetary and other models may pose some challenges in applications.
\end{abstract}

Keywords: EU; PPP; UIP; extended Mundell-Fleming model; generalized Box-Cox model.

JEL Classifications: F31; F41

\section{Introduction}

The exchange rate of the U.S. dollar against the euro (USD/EUR) has fluctuated over time. It was 1.1608 in 1999.M1, declined to a low of 0.8552 in 2000.M10, and rose to 1.5552 in 2008.M6. During 2000. M10-2008. M6, the euro appreciated $81.9 \%$. In recent months, partly due to the world financial crisis, movements in the USD/EUR exchange rate have caused some concerns. After reaching a high of 1.5923 on July 25, 2008 , it continued to decline to a low of 1.2701 on November 28, 2008. The $20.3 \%$ depreciation of the euro against the U.S. dollar in less than four months suggests that it is appropriate to re-examine macroeconomic fundamentals of the behaviour of the USD/EUR exchange rate in order to determine whether different exchange rate models can explain recent depreciation of the euro against the U.S. dollar.

This paper re-examines the behaviour of the USD/ EUR exchange rate based on the purchasing power parity (PPP) model, the uncovered interest parity (UIP) model, the monetary model, and the extended Mundell-Fleming model with several focuses. First, both the consumer price index (CPI) and the producer price index (PPI) are considered in the PPP model in order to determine which price index would be more appropriate (Taylor, A. M. and Taylor, M. P. 2004; Taylor 2006). Second, the generalized Box-Cox model (Greene 2003) is applied to test whether the widely used log-log functional form in the PPP model is appropriate. Third, in the monetary model, the Dornbusch (1976), Bilson (1978), Frenkel (1976), and Frankel (1979) versions are tested to determine which version works better. Fourth, in the extended Mundell-Fleming model, the financial stock value, the exchange rate, and the foreign interest rate are considered in the money demand function, and the interest parity condition is included in the simultaneous equations.

\section{Literature survey}

Several recent articles examine the dollar/euro exchange rate. Clostermann and Schnatz (2000) identify four fundamental factors affecting the real euro/dollar exchange rate. These are the relative real interest rate, the relative price, the relative fiscal position, and the real oil price. They find that a single-equation error correction model performs better than multivari- 
ate models in the medium term. Galati and Ho (2003) show that the euro/dollar exchange rate exhibits an asymmetric response to macroeconomic news, seems to ignore good news and remain preoccupied with bad news from the euro zone, and is affected more strongly when switching from good to bad macroeconomic news. Salvatore (2005) indicates that the euro/dollar exchange rate is hard to predict mainly because it is very difficult to precisely model news and unexpected events and because models are unable to take into consideration all the fundamentals at work.

Haushofer et al. (2005) examine fundamental and nonfundamental factors of the euro/dollar exchange rate during 2002-2003. They find that increasing trade deficits and a weak job market contributed to the strengthening of the euro and weakening of the U.S. dollar, that fears of terrorism and war and accounting scandals in the U.S. strained the U.S. dollar, and that foreign exchange trading agents followed buy and sell recommendations to make the euro stronger. Altavilla (2008) studies relationship between the euro/dollar exchange rate and the fundamentals based on a nonlinear modelling. He finds that the relationship is unstable and that when the euro/dollar exchange rate is near its equilibrium value, it would be less sensitive to any shock in the underlying fundamentals.

Sosvilla-Rivero and Garcia (2005) use the PPP model with the inflation expectations differential derived from government indexed bonds to forecast the dollar/euro exchange rate and reveal that the forecast performance is better than the random walk model for up to 5 days. Schnatz (2007) shows that euro exchange rates exhibit nonlinear patterns and that market forces will bring the euro exchange rates back towards the PPP equilibrium from any deviation.

Nautz and Ruth (2005) indicate that when insights from money demand studies are considered, monetary exchange rate models improve their empirical performance. Jyvaskyla (2006) includes equity markets and time-varying effects in the monetary exchange rate model and finds that the effect of the fundamentals is time-dependent. Karfakis (2006) studies the dollar/ euro exchange rate based on monetary fundamentals and shows that the exchange rate, the relative income, and the relative money supply are cointegrated and that the error-correction model can explain most of shortterm volatility and performs better than the random walk model.

\section{Theoretical model}

We can express the PPP Model, the UIP model, and the monetary model as:

$$
\begin{aligned}
\varepsilon= & \mathrm{f}(\text { relative price }), \\
\varepsilon= & \mathrm{g}(\text { relative interest rate, } \\
& \text { expected exchange rate }), \\
\varepsilon= & \mathrm{h}(\text { relative money supply, relative } \\
& \text { real output, relative interest rate }), \\
\varepsilon= & \mathrm{w}(\text { relative money supply, relative } \\
& \text { real output, relative expected } \\
& \text { inflation rate }), \\
\varepsilon= & \mathrm{v}(\text { relative money supply, relative } \\
& \text { real output, relative interest rate, } \\
& \text { relative expected inflation rate }),
\end{aligned}
$$

where $\varepsilon=$ the nominal exchange rate measured as units of the U.S. dollar per euro. The sign of the relative price level in equation (1) should be positive, suggesting that if the price level in the U.S. rises relative to the price level in the EU, the U.S. dollar will depreciate against the euro. The sign of the relative interest rate in equation (2) should be negative, implying that if the interest rate in the U.S. rises relative to the interest rate in the EU, the U.S. dollar is expected to appreciate.

The sign of the relative interest rate in equation (3) is positive in the Bilson (1978) model and negative in the Dornbusch (1976) model. The sign of the relative expected inflation rate in equation (4) is positive in the Frenkel (1976) model. In the Frankel (1979) model in equation (5), the sign of the relative interest rate is negative, and the sign of the relative expected inflation rate is positive.

In the extended Mundell-Fleming model (Romer 2003), suppose that aggregate spending is a function of real output, the real interest rate, real government spending, real government revenues, the real stock price, and the real exchange rate, that real money demand is determined by the nominal interest rate, real output, the real stock price, the real exchange rate, and the EU interest rate, and that the real exchange rate is a function of the interest rate differential between the U.S. and the EU. Solving for three endogenous variables of real output, the nominal interest rate and the real exchange rate, we can express the equilibrium real exchange rate as:

$$
\bar{E}=\bar{E}\left(M, G, T, S, r^{\prime}, \pi^{e}\right),
$$

where:

$E=$ the real USD/EUR exchange rate, (An increase means real depreciation of the U.S. dollar.)

$M=$ real money supply in the U.S.,

$G=$ real government spending in the U.S.,

$T=$ real government tax revenues in the U.S.,

$S=$ the real stock price in the U.S.,

$r^{\prime}=$ the nominal interest rate in the EU, and

$\pi^{e}=$ the expected inflation rate in the U.S. 
We expect that more monetary aggregate, more government taxes, and/or higher expected inflation rates would cause real depreciation of the U.S. dollar against the euro and that more government spending would lead to real appreciation of the U.S. dollar. The sign of the real stock value or the EU interest rate is unclear mainly because the sign of the real stock value or the EU interest rate in the U.S. money demand function could be positive or negative. For more detailed analysis of the fiscal, monetary and inflationary issues for the EU, see Sergi $(1998,1999,2000)$.

\section{Data and empirical results}

All the data were taken from the October 2008 issue of the International Financial Statistics published by the International Monetary Fund. The nominal exchange rate is measured as units of the U.S. dollar per euro. The real exchange rate is equal to the nominal exchange rate times and the relative price in the EU and the U.S. Both the consumer price index (CPI) and the producer price index (PPI) are considered in testing the PPP model. The U.S. federal funds rate and the euro overnight rate are selected to represent the relative interest rates. The lagged nominal exchanged rate is selected as a proxy for the expected nominal exchange rate. M2 is chosen to represent the money supply and measured in billions. Industrial production, which is an index number with 2000 as the base year, is chosen to represent real output because real GDP is not available on a monthly basis. The lagged inflation rate derived from the percent change in the consumer price index is selected to represent the expected inflation rate. To reduce a high degree of multicollinearity among government spending, government revenues and other right-hand side variables, real government deficit $\mathrm{G}-\mathrm{T}$ is used in empirical work. The real stock price index is equal to the nominal share price (with 2000 as the base year) adjusted for the CPI. The U.S. interest rate is represented by the federal funds rate, and the EU interest rate is represented by the EU overnight rate. Variables with positive values are measured in the log scale unless stated otherwise. Monthly data are used. Sample periods begin in 1999.M1 or 1999. M2 and end in 2008.M5 or 2008.M6 and are reported with estimated regressions.

Fig. 1 exhibits the USD/EUR exchange rates and the trade-weighted effective exchange rates during the sample period 1999.M1-2000.M10. As shown, the U.S. dollar appreciated during 1999.M1-2000.M10 and continued to exhibit a trend of depreciation after 2000. M10 except for most of the months in 2005. It seems that the nominal and real exchange rates followed simi- lar patterns. The nominal effective exchange rate rose in 1998, declined during 1999.M1-2000.M10, and showed a rising trend after 2000.M10. The real effective exchange rate follows a similar pattern.

Table 1 presents estimated coefficients, t-statistics in the parenthesis, values of adjusted $\mathrm{R}^{2}$, and mean absolute percent errors (MAPEs). To correct for both heteroscedasticity and autocorrelation when their forms are unknown, the Newey and West (1987) method is employed in estimating the consistent covariance and standard errors. In the PPP model based on the relative CPI, the coefficient of the relative CPI is positive and significant at the $1 \%$ level, the value of adjusted $\mathrm{R}^{2}$ is 0.498 , and the MAPE is 9.785 . In the PPP model based on the relative PPI, the coefficient of the relative PPI is positive and significant at the $1 \%$ level, the value of adjusted $\mathrm{R}^{2}$ is 0.748 , and the MAPE is 6.537 . In comparison, the PPP model with the relative PPI outperforms the PPP model with the relative CPI in the explanatory power and the forecast error. The Wald test is performed to determine whether the slope coefficient is equal to unity. The result shows that the F-statistic is far greater than the critical value. Hence, the null hypothesis that the coefficient is equal to unity can be rejected at the $1 \%$ level.

In the UIP model, the coefficient of the relative interest rate is negative and significant at the $1 \%$ level, and the coefficient of the expected exchange rate is positive and highly significant. Although the value of adjusted $\mathrm{R}^{2}$ is 0.981 , the MAPE of 29.838 is relatively high.

In the monetary model, three different versions are estimated and presented. In the version with the relative money supply, the relative real output, and the relative interest rate, the coefficients are significant at the 1\% level. However, the signs of the relative money supply and the relative output are unexpected. The value of adjusted $\mathrm{R}^{2}$ is 0.632 , and the MAPE is 8.053 . Hence, the Bilson or Dornbusch version cannot be confirmed. In the Frenkel version, the coefficient of the relative money supply has an unexpected negative sign and is significant at the $1 \%$ level, and the coefficients of the relative real output and the expected inflation rate are insignificant at the $10 \%$ level. The value of adjusted $\mathrm{R}^{2}$ is 0.521 , and the MAPE is 8.830 . Hence, there is lack of support for the Frenkel version. In the Frankel version, except that the coefficient of the relative interest rate is negative and significant at the $1 \%$ level, other coefficients either have the unexpected signs or are insignificant. The value of adjusted $\mathrm{R}^{2}$ is 0.629 , and the forecast error as measured by the MAPE is 8.059 . Thus, the Frankel version does not apply to the dollar/ euro exchange rate. 

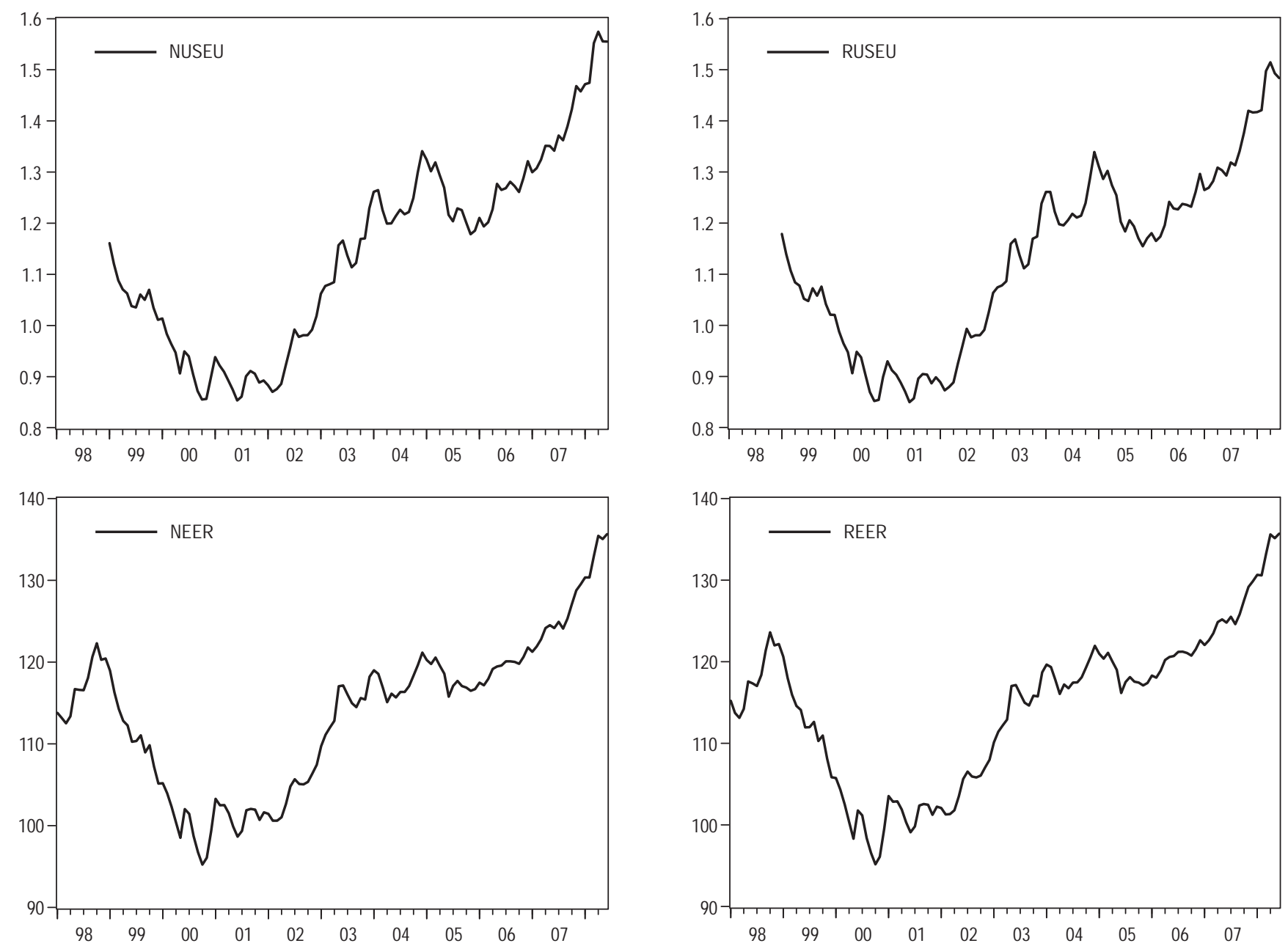

Notes:

NUSEU $=$ the nominal USD/EUR exchange rate.

RUSEU $=$ the real USD/EUR exchange rate.

NEER $=$ nominal effective exchange rate of the U.S. dollar. REER $=$ real effective exchange rate of the U.S. dollar.

Fig. 1. The nominal and real exchange rates

In the extended Mundell-Fleming model, due to the insignificant coefficient of real government deficit, it is deleted from the regression. The insignificant coefficient of real government deficit may not be surprising as Taylor (2000) indicates that the effect of deficitfinanced government spending on real output may be unclear due to time lags, crowding-out of private investment spending, rising interest rates, and other factors. Ricardian equivalence hypothesis (Barro 1989) also suggests that deficit-financed government spending may have a neutral effect in the long-run. The value of adjusted $\mathrm{R}^{2}$ is 0.732 , and the MAPE is 5.506 . The coefficients of real M2, the real stock price and the euro interest rate are significant at the $1 \%$, and the coefficient of the expected inflation rate is significant at the $10 \%$ level. Less quantity of money, a lower real stock price, a higher euro interest rate, and a lower expected inflation rate would lead to real appreciation of the U.S. dollar.
Several other versions are considered to test the robustness of the regression results and reported in Table 2. To determine whether the log-log functional form between the nominal exchange rate and the relative price may be appropriate, the generalized Box-Cox model (Greene 2003) is applied. In the regression using the relative $\mathrm{CPI}$, its coefficient is positive and significant at the $1 \%$ level. The transformation parameter is estimated to be 1.74. The log-likelihood function is estimated to be 69.990 and 75.374 for the generalized Box-Cox model and the log-log form, respectively. Based on the likelihood-ratio test, the log-log form using the relative CPI can be rejected at the $1 \%$ level. In the regression using the relative PPI, its coefficient is positive and significant at the $1 \%$ level. The transformation parameter is estimated to be 1.58 . The log-likelihood function is -115.488 for the generalized Box-Cox model and -110.053 for the log-log form. Applying the likelihoodratio test, the null hypothesis that the correct functional form is $\log -\log$ can be rejected at the $1 \%$ level. 
Table 1. Estimated regressions of the USD/EUR exchange rate

PPP Model: 1999.M1-2008.M6 for relative CPI; 1999.M1-2008.M5 for relative PPI

$\log \varepsilon=0.048+7.476 \log C P I^{*}$

(1.568) (6.851)

$\log \varepsilon=0.025+2.998 \log P P I^{*}$

(1.267) (11.168)

UIP Model: 1999.M2-2008.M6

$\log \varepsilon=0.001-0.011 \log r^{*}+1.012 \log \varepsilon^{e}$

$$
\text { (0.424) (-2.704) (77.182) }
$$

Monetary Model: 1999.M1-2008.M5

Bilson or Dornbusch Version

$\log \varepsilon=0.590-3.593 \log m^{*}+2.437 \log y^{*}-0.151 \log r^{*}$

$$
\text { (11.148) (-9.446) (3.063) (-4.081) }
$$

Frenkel Version

$\log \varepsilon=0.425-2.595 \log m^{*}+0.208 \log y^{*}+0.016 \pi^{e^{*}}$

$$
(10.134)(-7.309) \quad(0.256) \quad(0.939)
$$

Frankel Version

$\log \varepsilon=0.588-3.586 \log m^{*}+2.403 \log y^{*}-0.151 \log r^{*}+0.009 \pi^{e^{*}}$

$$
\begin{array}{llll}
(11.107)(-9.420) & (3.006) \quad(-4.047) & (0.571)
\end{array}
$$

Adj. $\mathrm{R}^{2}=0.498$

$\mathrm{MAPE}=9.785$

Adj. $R^{2}=0.748$

$\mathrm{MAPE}=6.537$

Adj. $\mathrm{R}^{2}=0.981$

MAPE $=29.838$

Adj. $R^{2}=0.632$

$\mathrm{MAPE}=8.053$

Adj. $R^{2}=0.521$

$\mathrm{MAPE}=8.830$

Adj. $R^{2}=0.629$

$\mathrm{MAPE}=8.059$

Extended Mundell-Fleming Model: 1999.M1-2008.M6

$\log E=-13.790+1.340 \log \mathrm{M}+0.566 \log S-0.173 \log r^{\prime}+0.037 \pi^{e}$

Adj. $R^{2}=0.732$

$$
(-15.169)(15.177) \quad(6.772) \quad(-5.960) \quad(1.694)
$$

$\mathrm{MAPE}=5.506$

\section{Notes:}

Figures in the parenthesis are t-statistics. $C P I^{*}=$ the relative consumer price index in the U.S. and the EU; $P P I^{*}=$ the relative producer price index in the U.S. and the EU; $r^{*}=$ the relative interest rate in the U.S. and the EU; $\varepsilon^{e}=$ the expected nominal exchange rate; $m^{*}=$ the relative money supply in the U.S. and the EU; $y^{*}=$ the relative real output in the U.S. and the EU; and $\pi^{e^{*}}=$ the relative expected inflation rate in the U.S. and the EU.

Table 2. Estimated regressions of the USD/EUR exchange rate for other versions

PPP Model: 1999.M1-2008.M6 for relative CPI; 1999.M1-2008.M5 for relative PPI

$\left(\varepsilon^{\lambda}-1\right) / \lambda=0.064+9.900\left[\left(C P I / C P I^{*}\right)^{\lambda}-1\right] / \lambda$

(4.243) (12.320)

$\left(\varepsilon^{\lambda}-1\right) / \lambda=0.037+3.527\left[\left(P P I / P P I^{*}\right)^{\lambda}-1\right] / \lambda$

$(3.475)(20.000)$

UIP Model: $1999 . \mathrm{M} 5-2008 . \mathrm{M} 6$
$\begin{aligned} \log \varepsilon= & 0.002-0.028 \log r^{*}+1.048 \log \left(\sum_{i=1}^{4} \varepsilon_{t-i}^{e}\right) / 4 \\ & (0.345)(-3.293)\end{aligned}$

Extended Mundell-Fleming Model: 1999.M1-2008.M6

$\log \mathrm{E}=-13.732+1.335 \log \mathrm{M}+0.561 \log \mathrm{S}-0.174 \log r^{\prime}+0.072\left(\sum^{4} \pi_{t-i}\right) / 4$
Adj. $\mathrm{R}^{2}=0.571$

MAPE $=10.136$

$\lambda=1.74$

Adj. $R^{2}=0.781$

$\mathrm{MAPE}=6.424$

$\lambda=1.58$

Adj. $\mathrm{R}^{2}=0.961$

$\mathrm{MAPE}=2.703$

Notes:

$\lambda=$ is the Box-Cox transformation parameter. 
If the average exchange rate of past four months is chosen as a proxy for the expected exchange rate in the UIP model, its coefficient is positive and significant at the $1 \%$ level. The forecast error of 2.703 is much smaller than 29.838 when the simple lagged exchange rate is used as a proxy for the expected inflation rate. If the average inflation rate in past four months is selected to represent the expected inflation rate in the extended Mundell-Fleming model, its coefficient has a smaller standard error and is more significant. Other results are similar.

\section{Conclusion}

In this article, we have examined the movements in the dollar/euro exchange rate based on the PPP model, the UIP model, the monetary model, and the extended Mundell-Fleming model. The coefficients of the relative money supply, the relative real output and the relative expected inflation rate in the monetary model either have the unexpected signs or are insignificant. The coefficient of real government deficit in the extended Mundell-Fleming model is insignificant. The extended Mundell-Fleming model has the smallest forecast error, followed by the monetary model, the PPP model using the relative PPI, the PPP model using the relative CPI, and the UIP model. If the average exchange rate of past four months is used to represent the expected exchange rate, the UIP model will have the smaller forecast error.

There are several policy implications. The PPI needs to be monitored closely as the relative PPI exhibits a smaller forecast error and a higher explanatory power in the PPP model. The functional form in the PPP model should be tested to determine whether the widely used log-log form may be appropriate. If the $\log -\log$ form can be rejected, it implies that the elasticity of the nominal exchange rate with respect to the relative price would vary. The unexpected signs or insignificant coefficients in the monetary model suggest that its application may be subject to more scrutiny. It seems that the extended Mundell-Fleming model provides policymakers with more analytical tools as it includes major economic theories, considers the money market, and incorporates international capital flows as well.

There may be areas for future research. One may construct the expected exchange rate and the expected inflation rate with more advanced methodologies. Other relevant variables may be included in the extended Mundell-Fleming model. One may consider replacing the money demand function with the monetary policy function. If the data are available, the debt/GDP ratio may be considered as another fiscal policy variable to determine whether there may be a sustainable debt/ GDP ratio and whether a higher debt/GDP ratio would affect the equilibrium real GDP.

\section{References}

Altavilla, C. 2008. The UN stable relationship between the exchange rate and its fundamentals, Applied Economics Letters 15(7/9): 539-544. doi:10.1080/13504850600706610

Barro, R. J. 1989. The Ricardian approach to budget deficits, Journal of Economic Perspectives 3(2): 37-54.

Bilson, J. F. O. 1978. Rational expectations and the exchange rate, in Frenkel, J. and Johnson, H. (Eds.). The Economics of Exchange Rates. Reading: Addison-Wesley Press.

Clostermann, J.; Schnatz, B. 2000. The determinants of the Euro-Dollar exchange rate: synthetic fundamentals and a non-existing currency, Konjunkturpolitik 46(3): 274-302.

Dornbusch, R. 1976. Expectations and exchange rate dynamics, Journal of Political Economy 84(6): 1161-1176. doi:10.1086/260506

Frankel, J. A. 1979. On the mark: a theory of floating exchange rates based on real interest differentials, American Economic Review 69(4): 610-622.

Frenkel, J. A. 1976. A monetary approach to the exchange rate: doctrinal aspects and empirical evidence, Scandinavian Journal of Economics 78(2): 200-224. doi:10.2307/3439924

Galati, G.; Ho, C. 2003. Macroeconomic news and the Euro/ Dollar exchange rate, Economic Notes 32(3): 371-398. doi:10.1111/1468-0300.00118

Greene, W. H. 2003. Econometric Analysis. 5th edition. NJ: Prentice Hall.

Haushofer, H.; Moser, G.; Schardax, F., and Unger, R. 2005. Fundamental and nonfundamental factors in the Euro/U.S. dollar market in 2002 and 2003, Monetary Policy and the Economy 1: 58-76.

Karfakis, C. 2006. Is there an empirical link between the Dollar price of the Euro and the monetary fundamentals? Applied Financial Economics 16(13): 973-980.

doi:10.1080/09603100600638969

Jyvaskyla, U. 2006. Time-varying fundamentals of the Euro-Dollar exchange rate, International Economic Journal 20(4): 385-407. doi:10.1080/10168730600883515

Nautz, D. and Ruth, K. 2005. Monetary disequilibria and the Euro/Dollar exchange rate. Available from Internet: $<$ http://www.bundesbank.de/download/volkswirtschaft/ dkp/2005/200518dkp.pdf $>$.

Newey, W. K. and West, K. D. 1987. A simple, positive semi-definite, heteroskedasticity and autocorrelation consistent covariance matrix, Econometrica 55(3): 703-708. doi: $10.2307 / 1913610$

Romer, D. 2003. Advanced Macroeconomics. Second edition. NY: McGraw-Hill/Irwin. 
Salvatore, D. 2005. The Euro-Dollar exchange rate defies prediction, Journal of Policy Modeling 27(4): 455-464. doi:10.1016/j.jpolmod.2005.04.011

Schnatz, B. 2007. Is reversion to PPP in Euro exchange rates non-linear? International Economics and Economic Policy 4(3): 281-297. doi:10.1007/s10368-007-0091-7

Sergi, B. S. 1998. External inflationary incentives in Europe: how and why they moved in the 1980s, Économie Appliquée 51(2): 123-137.

Sergi, B. S. 1999. Fiscal issues in post-communist economies: a 'pragmatic' and 'aggressive' fiscal rule, Prague Economic Papers 8(1): 14-26.

Sergi, B. S. 2000. A new index of independence of $12 \mathrm{Eu}-$ ropean national banks: the 1980s and early 1990s, Journal of Transnational Management Development 5(2): 41-57. doi:10.1300/J130v05n02_04

Sosvilla-Rivero, S.; Garcia, E. 2005. Forecasting the Dollar/ Euro exchange rate: are international parities useful? Journal of Forecasting 24(5): 369-337. doi:10.1002/for.955

Taylor, A. M.; Taylor, M. P. 2004. The purchasing power parity debate, Journal of Economic Perspectives 18(4): 135-158. doi:10.1257/0895330042632744

Taylor, M. P. 2006. Real exchange rates and purchasing power parity: mean-reversion in economic thought, Applied Financial Economics 16(1/2): 1-17. doi:10.1080/09603100500390067

Taylor, J. B. 2000. Reassessing discretionary fiscal policy, Journal of Economic Perspectives 14(3): 21-36. 